\title{
Cell Death Triggers Olfactory Circuit Plasticity via Glial Signaling in Drosophila
}

\author{
Hokto Kazama, Emre Yaksi, and Rachel I. Wilson \\ Department of Neurobiology, Harvard Medical School, Boston Massachusetts 02115
}

The Drosophila antennal lobe is organized into glomerular compartments, where olfactory receptor neurons synapse onto projection neurons. Projection neuron dendrites also receive input from local neurons, which interconnect glomeruli. In this study, we investigated how activity in this circuit changes over time when sensory afferents are chronically removed in vivo. In the normal circuit, excitatory connections between glomeruli are weak. However, after we chronically severed receptor neuron axons projecting to a subset of glomeruli, we found that odor-evoked lateral excitatory input to deafferented projection neurons was potentiated severalfold. This was caused, at least in part, by strengthened electrical coupling from excitatory local neurons onto projection neurons, as well as increased activity in excitatory local neurons. Merely silencing receptor neurons was not sufficient to elicit these changes, implying that severing receptor neuron axons is the relevant signal. When we expressed the neuroprotective gene Wallerian degeneration slow $\left(\right.$ Wld ${ }^{S}$ ) in receptor neurons before severing their axons, this blocked the induction of plasticity. Because expressing Wld ${ }^{S}$ prevents severed axons from recruiting glia, this result suggests a role for glia. Consistent with this, we found that blocking endocytosis in ensheathing glia blocked the induction of plasticity. In sum, these results reveal a novel injury response whereby severed sensory axons recruit glia, which in turn signal to central neurons to upregulate their activity. By strengthening excitatory interactions between neurons in a deafferented brain region, this mechanism might help boost activity to compensate for lost sensory input.

\section{Introduction}

In several regions of the mammalian cortex, silencing some portion of the afferent sensory input to that region can trigger a functional reorganization of sensory representations. Responses evoked by deprived afferents are often weakened or abolished, whereas responses evoked by untreated (or control) afferents often spread to encompass neurons that were previously unresponsive to these afferents. For example, monocular deprivation causes the representation of the spared eye to take over regions of the visual cortical map that were previously dedicated to the deprived eye (Wiesel, 1982). Similarly, plucking a whisker on the rodent face causes representations of the spared whiskers to spread over somatosensory cortical territory that would normally be occupied by the plucked whisker (Feldman and Brecht, 2005). The cellular mechanisms of these processes are not fully

Received Nov. 15, 2010; revised March 29, 2011; accepted April 11, 2011.

Author contributions: H.K. and R.W. designed research with input from E.Y.; H.K. performed research except for Figure 2, which is by E.Y.; H.K. analyzed data except for Figure 2, which is by E.Y.; H.K. and R.W. wrote the paper with input from E.Y.

This work was funded by a postdoctoral fellowship from the NIH (F32DC009538 to H.K.), a Human Frontiers Science Program long-term fellowship (to E.Y.), a research project grant from the NIH (R01DC008174), a McKnight Scholar Award, and a Beckman Young Investigator Award (to R.I.W.). R.I.W. is a HHMI Early Career Scientist. We thank Marc Freeman, Kei Ito, Toshihiro Kitamoto, Liqun Luo, Gero Miesenböck, Dean Smith, and Reinhard Stocker for gifts of fly stocks. Shawn Olsen contributed to pilot experiments.

Correspondence should be addressed to Rachel I. Wilson, Department of Neurobiology, Harvard Medical School, 220 Longwood Avenue, Boston MA 02115. E-mail: rachel_wilson@hms.harvard.edu.

H. Kazama's present address: RIKEN Brain Science Institute, 2-1 Hirosawa, Wako, Saitama 351-0198, Japan.

E. Yaksi's present address: Neuroelectronics Research Flanders, Kapeldreef 75, 3001 Leuven, Belgium.

DOI:10.1523/JNEUROSCI.5984-10.2011

Copyright $\odot 2011$ the authors $\quad 0270-6474 / 11 / 317619-12 \$ 15.00 / 0$ understood, but multiple sites and mechanisms are clearly involved (Feldman, 2009; Smith et al., 2009; Tropea et al., 2009).

Insights into complex biological events often come from simple model systems. Drosophila melanogaster is an example of a relatively simple organism having well defined sensory maps. Visual, somatosensory, olfactory, and gustatory afferents in the fly form orderly projections to the CNS (Strausfeld, 1976), suggesting that the fly might be a useful model for studying mechanisms underlying the plasticity of central sensory representations.

In particular, there is already evidence that the first olfactory region of the Drosophila brain, the antennal lobe, can undergo plasticity in adult life. The antennal lobe consists of $\sim 50$ compartments, termed glomeruli. All the olfactory receptor neurons (ORNs) that express the same odorant receptor gene send their axons to the same glomerulus (Vosshall et al., 2000). Almost every projection neuron (PN) is postsynaptic to a single glomerulus (Stocker et al., 1990) and so receives direct input from just a single ORN type. Glomeruli are linked by both inhibitory and excitatory connections, and these are mediated by distinct classes of local neurons (LNs) (Olsen et al., 2007; Shang et al., 2007; Chou et al., 2010; Huang et al., 2010; Yaksi and Wilson, 2010). A recent study found that rearing flies in the presence of an odorant that specifically activates one receptor causes a physical expansion of the glomerulus corresponding to that receptor, leaving other glomeruli unaffected (Sachse et al., 2007). This expansion reflects increased innervation of the affected glomerulus by inhibitory LNs. In another study, it was found that pairing an odorant with an electric shock potentiated responses of PNs in certain glomeruli to the conditioned odor (Yu et al., 2004), again demonstrating that the adult antennal lobe is capable of functional 
changes. However, it is not known whether sensory deprivation can trigger plasticity in this structure.

In this study, we asked whether neural activity in the antennal lobe is altered over time after chronic removal of ORN input to a subset of glomeruli. Our findings reveal a novel form of plasticity that involves signaling between severed axons, glia, and surviving neurons.

\section{Materials and Methods}

Fly stocks. Flies were raised on conventional cornmeal agar medium on a $12 \mathrm{~h}$ light/dark cycle at $25^{\circ} \mathrm{C}$, except for some experiments using flies carrying the UAS-shibire ${ }^{\text {tsl }}$ transgene, where they were raised at $30^{\circ} \mathrm{C}$ after eclosion to block the function of mutant dynamin. All experiments were performed on female flies $2 \mathrm{~d}$ post-eclosion [except in Figs. $1 G$ and $7 A$ (shown in Results), where some flies were $5 \mathrm{~d}$ old]. The genotypes used in each figure were as follows: Figure 1 A-D, NP5103-Gal4,UAS-CD8:GFP; Figure $1 E-H$, NP7217Gal4,UAS-CD8:GFP; Figures 2 and 3, krasavietz-Gal4,UAS-CD8:GFP; Figure 4A,B, NP5221-Gal4,UAS-CD8:GFP;krasavietz-Gal4,UAS-CD8:GFP; Figure 4C-E, NP5103-Gal4,UAS-CD8:GFP; Figure 4F-H, NP7273Gal4,UAS-CD8:GFP; Figure 5, NP5103-Gal4,UAS-CD8:GFP and NP5103Gal4,UAS-CD8:GFP;Or43b ${ }^{1}$; Figure 6, NP7217-Gal4,UAS-CD8:GFP and NP7217-Gal4,UAS-CD8:GFP;;Or83b ${ }^{2}$; Figure 7A, pebbled-Gal4/w ${ }^{1118}$;

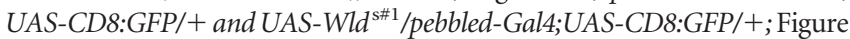
$7 B-D, U A S-W l d^{s \# 1} / p e b b l e d-G a l 4$ and UAS-Wld ${ }^{s \# 1} / w^{1118}$; Figure $8 A-C$, $U A S-$ shi $^{\text {ts1 }} / \mathrm{Mz} 0709-G a l 4$; Figure $8 D-F$, alrm-Gal4 ${ }^{\# 3} /+; U A S-$ shi $^{\text {ts1 }} /+$. Stocks were originally published as follows: NP5103-Gal4 and NP5221-Gal4 (Tanaka et al., 2004); NP7217-Gal4 (Kazama and Wilson, 2008); Or43b ${ }^{1}$ (Elmore et al., 2003); Mz0709-Gal4 (Ito et al., 1995); alrm-Gal4 (Doherty et al., 2009); UAS-Wld ${ }^{\text {s\#1 }}$ (X) (Hoopfer et al., 2006; MacDonald et al., 2006); krasavietz-Gal4 (Dubnau et al., 2003); GH298-Gal4 (Stocker et al., 1997); UAS-shibire $^{\text {tsl }}$ (III) (Kitamoto, 2001); UAS-CD8:GFP (X) and UAS-CD8: GFP (II) (Lee and Luo, 1999).

$P N$ and $L N$ recordings. Whole-cell current-clamp recordings from $\mathrm{PN}$ and LN somata were performed as previously described (Wilson and Laurent, 2005). The internal patch-pipette solution used for currentclamp recordings contained the following (in $\mathrm{mM}$ ): 140 potassium aspartate, 10 HEPES, 4 MgATP, $0.5 \mathrm{Na}_{3} \mathrm{GTP}, 1$ EGTA, $1 \mathrm{KCl}$, and 13 biocytin hydrazide. The $\mathrm{pH}$ of the internal solution was adjusted to 7.3 and the osmolarity was adjusted to $\sim 265 \mathrm{mOsm}$. External saline contained the following (in mM): $103 \mathrm{NaCl}, 3 \mathrm{KCl}, 5 \mathrm{~N}$-tris(hydroxymethyl)methyl-2aminoethane-sulfonic acid, 8 trehalose, 10 glucose, $26 \mathrm{NaHCO}_{3}, 1$ $\mathrm{NaH}_{2} \mathrm{PO}_{4}, 1.5 \mathrm{CaCl}_{2}$, and $4 \mathrm{MgCl}_{2}$ (adjusted to $270-275 \mathrm{mOsm}$ ). The saline was bubbled with $95 \% \mathrm{O}_{2} / 5 \% \mathrm{CO}_{2}$ and reached a $\mathrm{pH}$ of 7.3 . Recordings were acquired with an Axopatch 200A amplifier (Molecular Devices) equipped with a CV 201A headstage ( $500 \mathrm{M} \Omega$ ) and an Axopatch 1D amplifier (Molecular Devices) equipped with a CV-4 headstage (500 $\mathrm{M} \Omega$ ). The membrane potential was held at $\sim-40,-45$, or $-55 \mathrm{mV}$, depending on the type of the experiment, but the membrane potential was always held at the same value for comparisons between parallel experimental treatments (chronic vs acute, etc.). Signals were low-pass filtered at $2 \mathrm{kHz}$ and digitized at $5 \mathrm{kHz}$. Voltages were uncorrected for the liquid junction potential $(+13 \mathrm{mV})$. In PNs postsynaptic to intact ORNs, we normally observe a high rate of spontaneous EPSPs (sEPSPs) several millivolts in amplitude. Each sEPSP of this size reflects a spontaneous spike in an ORN (Kazama and Wilson, 2008, 2009). In PNs postsynaptic to acutely removed antennae or palps, we occasionally observed some sEPSPs of this size immediately after ORN axons were severed (perhaps reflecting some ability of severed axons to initiate regenerative events), but the sEPSP rate generally decayed to zero over several minutes. In PNs postsynaptic to chronically severed axons [either wild type or Wallerian degeneration slow $\left(\mathrm{Wld}^{\mathrm{S}}\right.$ )-expressing], we never observed sEPSPs of this size. In some experiments, either $100 \mu \mathrm{M} \mathrm{Cd}^{2+}$ or $50 \mu \mathrm{M}$ mecamylamine (Sigma) was added to the external solution to block chemical synaptic transmission. To fluorescently label specific types of antennal lobe neurons and thereby target our electrodes to these neurons, we crossed selective Gal4 lines to a UAS-linked GFP reporter (UAS-CD8:GFP). The following Gal4 lines were used for this purpose: NP5103-Gal4 (drives Gal4 expression in at least 3 PNs in glomerulus VM2), NP7217-Gal4 (drives Gal4 expression in at least 3 PNs in glomerulus VM7, plus PNs in DL5, DM6, and VM2), NP5221-Gal4 (drives Gal4 expression in PNs in glomeruli DM1, VC1, VC2, and VA4), NP7273-Gal4 (drives Gal4 expression in $1 \mathrm{PN}$ in glomerulus V), and krasavietz-Gal4 [drives Gal4 expression in at least 2 antennal lobe excitatory LNs (eLNs) and sometimes 3]. We identified eLNs on the basis of previously published criteria (Yaksi and Wilson, 2010). Specifically, we defined eLNs as LNs that express Gal4 in the krasavietz-Gal4 line and that are barraged by spontaneous IPSPs (see Fig. 3B). In these cells we also typically saw both conventional spikes $(\sim 40 \mathrm{mV}$ amplitude) and small events resembling attenuated spikes ( $\sim 10 \mathrm{mV}$ amplitude), although occasionally the attenuated spikes were absent. When we recorded from a cell that fit these criteria at the same time that we recorded from a randomly selected PN, we always observed electrical coupling between the LN and the PN. In a previous study, we never saw spontaneous IPSPs or attenuated spikes in the inhibitory LNs that express Gal4 in this line (Yaksi and Wilson, 2010).

Olfactory stimulation. Odors used in this study were pentyl acetate, ethyl acetate, methyl salicylate, and 1,4-diaminobutane, plus a mixture designed to drive palp ORNs strongly (benzaldehyde, fenchone, ethyl butyrate, and pentyl acetate). All pure compounds were diluted 100-fold in paraffin oil (except 1,4-diaminobutane, which was diluted 100,000fold), and the headspace of the vial containing this solution was further diluted tenfold in air. Odors were delivered with a custom-built device described previously (Olsen et al., 2007). The flow rate of the odor delivery stream was $2.2 \mathrm{~L} / \mathrm{min}$. The end of the odor delivery tube had an inner diameter of $3.2 \mathrm{~mm}$ and it was positioned $8 \mathrm{~mm}$ from the fly. Stimuli were applied for $500 \mathrm{~ms}$ every $40 \mathrm{~s}$ for 5 or 6 trials per stimulus. The trial-to-trial stability of stimuli was confirmed with a photoionization detector (miniPID, Aurora Scientific; coefficient of variation $=0.015 \pm$ 0.003 for consecutive trials) (Kazama and Wilson, 2009).

Removal of antennae and palps. To remove antennal ORNs, the third antennal segment was detached with forceps where it joins the second antennal segment. To remove the maxillary palp, the entire maxillary palp was detached with forceps where it joins the proboscis. In either case, the associated ORN somata were completely removed, leaving behind only severed ORN axons. In the "chronic" configuration, either antennae or palps were removed within several hours after eclosion, and recordings were performed $2 \mathrm{~d}$ later [except in Fig. $1 G$ (see Results), where some recordings were performed $5 \mathrm{~d}$ later]. In the "acute" configuration, antennae or palps were removed from 2 -d-old flies, and recordings were typically initiated within $20 \mathrm{~min}$.

Immunohistochemistry. Each recorded $\mathrm{PN}$ was visualized with biocytin-streptavidin whenever we were targeting specific types of PNs. Immunohistochemistry with biocytin-streptavidin, anti-CD8, and nc82 was performed as described previously (Wilson and Laurent, 2005), except that in the secondary incubation we used 1:250 goat anti-mouse/ Alexa Fluor 633 and 1:1000 streptavidin/Alexa Fluor 568 (Invitrogen). The nc82 antibody was obtained from the Developmental Studies Hybridoma Bank (University of Iowa, Iowa City, IA).

Data analysis. All analyses were performed in IGOR Pro (Wavemetrics) using custom software. All mean values are reported as mean \pm SEM, averaged across experiments.

\section{Results}

\section{Olfactory circuit plasticity}

When all the ORNs innervating a subset of glomeruli are silenced or killed, the projection patterns of the surviving ORNs and the deafferented PNs are remarkably stable (Berdnik et al., 2006; Olsen et al., 2007). As severed ORN axons degenerate, ORNs innervating adjacent glomeruli do not expand into deafferented glomeruli. Also, PNs in deafferented glomeruli still maintain their dendrites within the borders of their target glomerulus. These findings convey the impression that the antennal lobe circuit is fixed. However, olfactory experience can alter odor-evoked responses in LNs (Sachse et al., 2007). We therefore hypothesized that LN activity and/or LN-PN interactions change over time if ORN input to some glomeruli is chronically removed. 
A acute
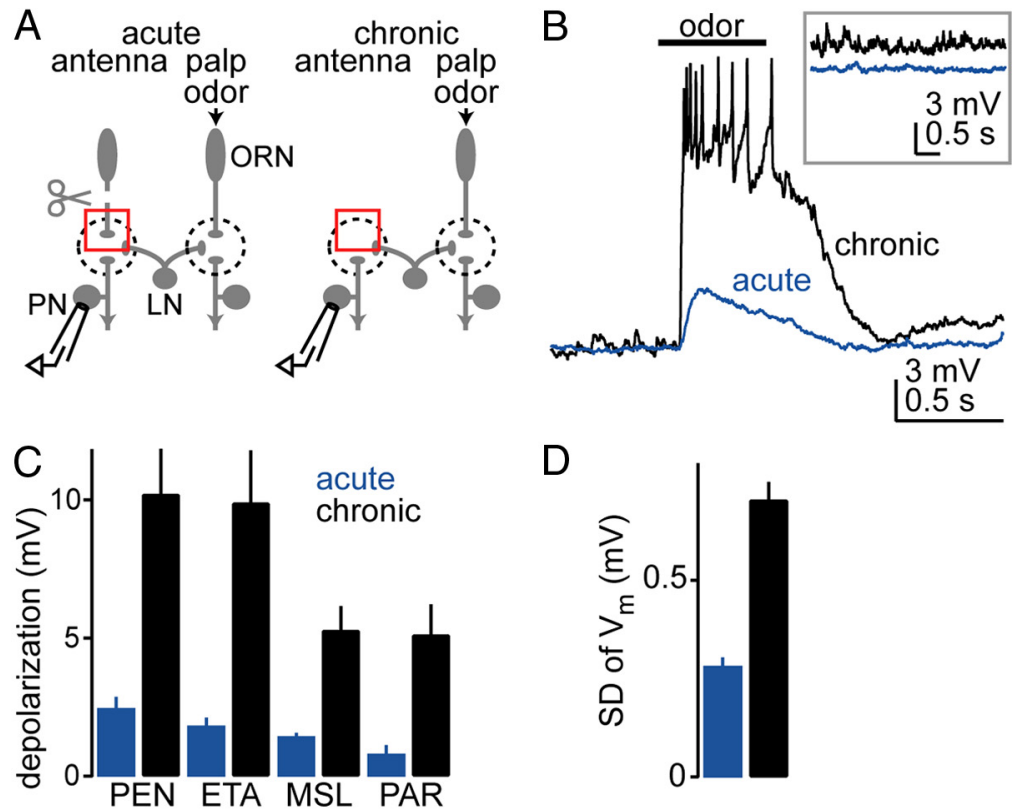

E
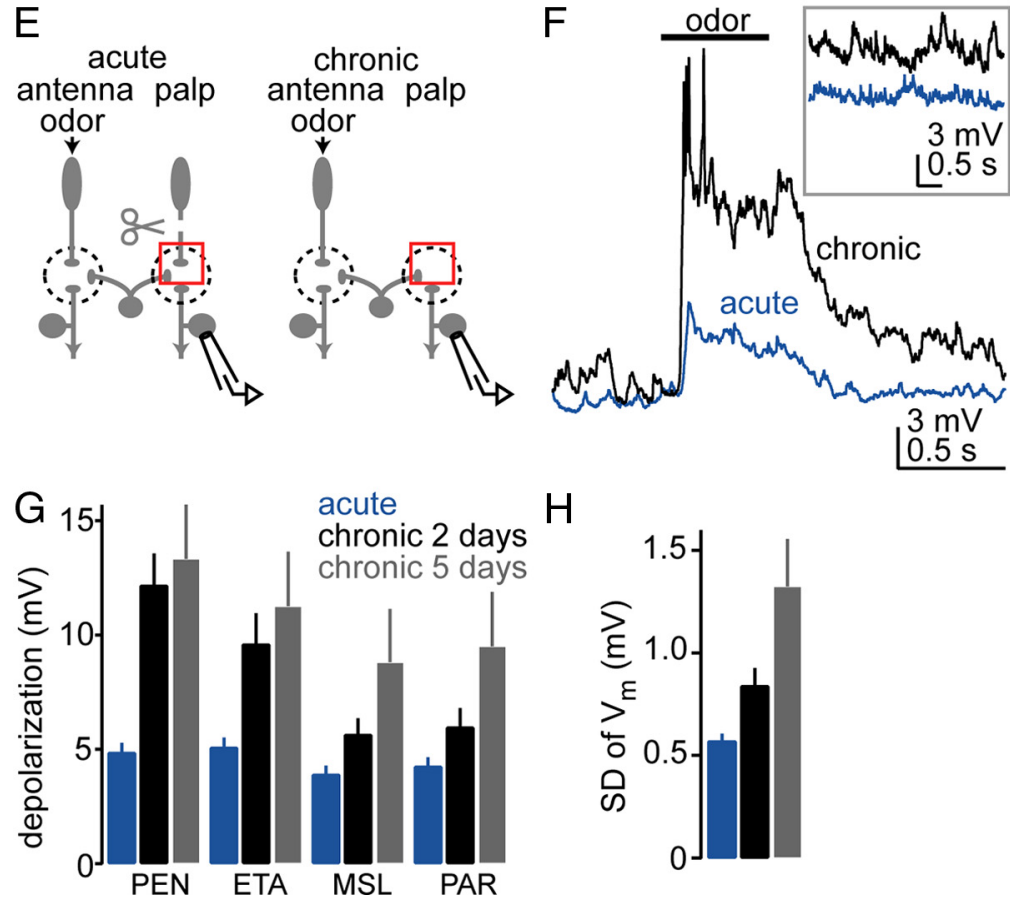

Figure 1. Lateral excitation is strengthened after some olfactory receptor neurons are chronically removed. $A$, We recorded from antennal PNs while stimulating the palps with odors. Antennae were removed either acutely or chronically (for $2 \mathrm{~d}$ ). Red boxes highlight the difference between the two experimental configurations. After chronic removal, severed olfactory receptor neuron axons degenerate. Dendrites of deafferented PNs and axons of surviving receptor neurons do not sprout across glomerular boundaries. LNs mediate interactions between glomeruli. $\boldsymbol{B}$, Whole-cell current-clamp recording from an antennal PN (glomerulus VM2). The typical odor-evoked depolarization is small after acute antennal removal, but much larger after chronic removal. Inset shows increased spontaneous membrane potential fluctuations after chronic removal. C, Average membrane potential change in VM2 PNs in response to four different odors [pentyl acetate (PEN), ethyl acetate (ETA), methyl salicylate (MSL), and paraffin oil (PAR)]. Depolarization is significantly larger after chronic removal ( $p<0.01$, two-way ANOVA, $n=5$ for each condition). $\boldsymbol{D}$, The magnitude of spontaneous membrane potential fluctuations in VM2 PNs is significantly larger after chronic removal (quantified as the SD over $8 \mathrm{~s}, p<0.05, t$ test, $n=5$ for each condition). $\boldsymbol{E}-\boldsymbol{H}$, Same as $\boldsymbol{A}-\boldsymbol{D}$, but here we chronically removed the palps and recorded from a palp PN (glomerulus VM7) while stimulating the antennae with odors. $G$, Odor-evoked depolarization is significantly larger after chronic removal of palps ( $p<0.01$, two-way ANOVA, $n=5$ for each condition). Waiting $5 \mathrm{~d}$ rather than $2 \mathrm{~d}$ produces even larger changes in deafferented PNs. $\boldsymbol{H}$, Spontaneous activity is also potentiated after chronic palp removal ( $p<$ 0.05 , one-way ANOVA, $n=5$ for each condition).
To test this idea, we exploited the fact that Drosophila ORNs are housed in two olfactory organs, the antenna and the maxillary palp. Antennal glomeruli and palp glomeruli are intermingled in the antennal lobe (Stocker et al., 1990; Couto et al., 2005; Fishilevich et al., 2005), and LNs make connections between the two types of glomeruli (Stocker et al., 1990; Chou et al., 2010). Most antennal ORNs (and all palp ORNs) project bilaterally. Thus, by removing both antennae, we selectively remove all ORN input to every antennal glomerulus. To record selectively from deafferented PNs (Fig. 1A), we labeled PNs in a specific antennal glomerulus (VM2) with GFP. Palp ORNs remain intact, and thus LNs can still be activated by odors.

First, we asked how these PNs respond to odors after acute removal of their ORN afferents. We removed the antennae just before the experiment, and made recordings selectively from VM2 PNs while stimulating the palps with odors. Under these conditions, every odor evoked a weak depolarization (Fig. $1 B$ ). This depolarization reflects excitatory input arising from other glomeruli (Olsen et al., 2007; Shang et al., 2007). This excitatory input is relayed to PNs by a specific class of LNs (termed eLNs) that have reciprocal excitatory interactions with PNs in most or all glomeruli (Huang et al., 2010; Yaksi and Wilson, 2010).

In contrast to acutely deafferented PNs, chronically deafferented VM2 PNs were robustly excited by odors. Odor stimuli now evoked much larger depolarizations and generally elicited a train of action potentials (Fig. $1 B$ ). On average, odor-evoked depolarizations increased severalfold for all odors (Fig. 1C). We also observed that spontaneous membrane potential fluctuations in these PNs were larger after chronic antennal removal compared with acute removal (Fig. 1B,D), consistent with increased excitatory input to these PNs.

Potentiated odor responses in deafferented PNs are likely to reflect potentiated excitation from eLNs, not ORNs. We infer this because filling deafferented PNs with biocytin confirmed that their dendrites do not extend into neighboring glomeruli, even after chronic ORN removal. We also confirmed that ORNs from neighboring glomeruli do not invade the deafferented glomeruli (data not shown). These results are consistent with previous studies showing that postsynaptic PNs and neighboring ORNs are morphologically stable after killing ORNs targeting a subset of glomeruli (Berdnik et al., 2006; Olsen et al., 
2007). Thus, increased excitatory input to these PNs likely arises from eLNs, not ORNs. The broad odor tuning of the potentiated responses in deafferented PNs is consistent with this conclusion, because each eLN arborizes in most or all glomeruli and, thus, likely pools many diverse ORN inputs (Huang et al., 2010; Yaksi and Wilson, 2010).

This phenomenon is not restricted to antennal glomeruli. This is clear from an additional set of experiments in which we recorded from GFP-labeled palp PNs and removed the palps, instead of recording from antennal PNs and removing the antennae (Fig. 1E). In these palp PNs (glomerulus VM7), we observed only weak excitation after acute palp removal, but robust excitation after chronic palp removal (Fig. 1F, G). Again, spontaneous activity was also potentiated (Fig. $1 \mathrm{H}$ ).

These results imply that chronically removing ORN input to a $\mathrm{PN}$ leads to the potentiation of excitatory input onto that PN from eLNs. This raises the question of what mechanisms underlie this potentiation.

\section{Strengthening of electrical coupling}

In the normal circuit, depolarization propagates between glomeruli via eLNs. Each eLN receives mixed chemical/electrical input from most PNs and makes electrical connections onto most PNs (Huang et al., 2010; Yaksi and Wilson, 2010). We therefore hypothesized that potentiated odor responses in chronically deafferented PNs reflect strengthened electrical coupling from eLNs onto PNs.

To test this idea, we made paired recordings from eLNs and PNs (Fig. 2A).We identified eLNs by labeling them with GFP, and also based on their characteristic electrophysiological properties (see Materials and Methods). Although we did not label or fill PNs in this experiment, most of the PNs we recorded from are likely to be antennal PNs, because $\sim 90 \%$ of glomeruli are postsynaptic to the antennae. We injected hyperpolarizing and depolarizing current into the eLN and monitored synaptic responses in the PN. In every pair we recorded from, both hyperpolarizing and depolarizing steps were transmitted across the synapse from the eLN to the PN (Fig. 2 B). This implies that each eLN makes an electrical synapse onto many (or all) PNs.

We compared the results of these paired recordings after either chronic or acute antennal removal. This revealed that after chronic antennal removal, coupling from eLNs onto PNs was substantially strengthened (Fig. $2 \mathrm{~B}, \mathrm{C}$ ). Like eLN-to-PN synapses in the normal circuit, eLN-to-PN synapses after chronic antennal removal were not significantly altered by adding a nicotinic acetylcholine receptor antagonist (mecamylamine $50 \mu \mathrm{M}$ ) (data not shown). Thus, like normal eLNto-PN synapses, these synapses seem to be purely electrical, with little or no chemical component.

Potentiated coupling could result from an increase in the conductance of the electrical synapse between these cells. Alterna- tively, it could reflect an increased ability of voltages to propagate between the soma and the site of electrical synapses. To test for this, we measured the input resistance of PNs and eLNs after either chronic or acute antennal removal. We found no significant differences in either cell type (Fig. 2D). This argues against the idea that increased coupling is the result of increased input resistance, although we cannot exclude this idea completely because we cannot measure input resistance in remote areas of the dendritic tree.

We also examined coupling in the reverse direction, from PNs onto eLNs. In the normal circuit, eLNs receive excitation from PNs via mixed chemical-electrical synapses (Huang et al., 2010; Yaksi and Wilson, 2010). In our dual recordings, we found that the strength of PN-to-eLN coupling was not significantly affected by chronic antennal removal (data not shown). Because electrical connections are bidirectional, one might expect to see bidirectional potentiation. There are three possible explanations for why we did not see this. First, because the electrical component of PN-to-eLN synapses is weaker than the chemical component (Huang et al., 2010; Yaksi and Wilson, 2010), any change in electrical coupling may be too small to see. Second, there might be a change in innexin composition that alters the degree of rectification at these electrical synapses. Third, although we do not find a change in eLN input resistance, we cannot exclude the idea that increased coupling from eLNs onto PNs reflects better voltage 
A

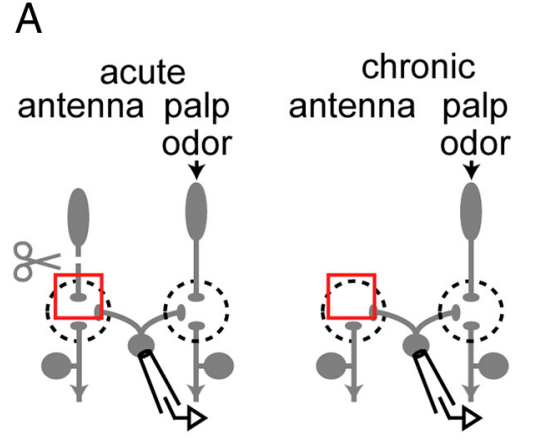

B

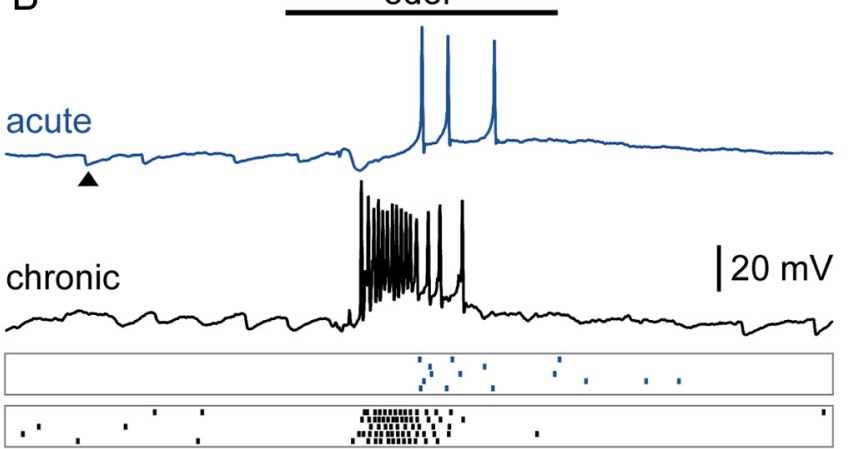

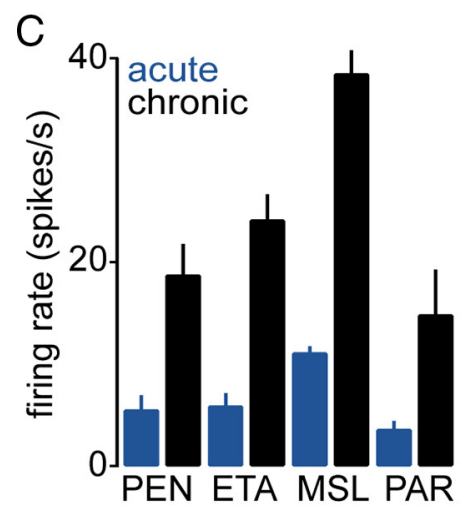
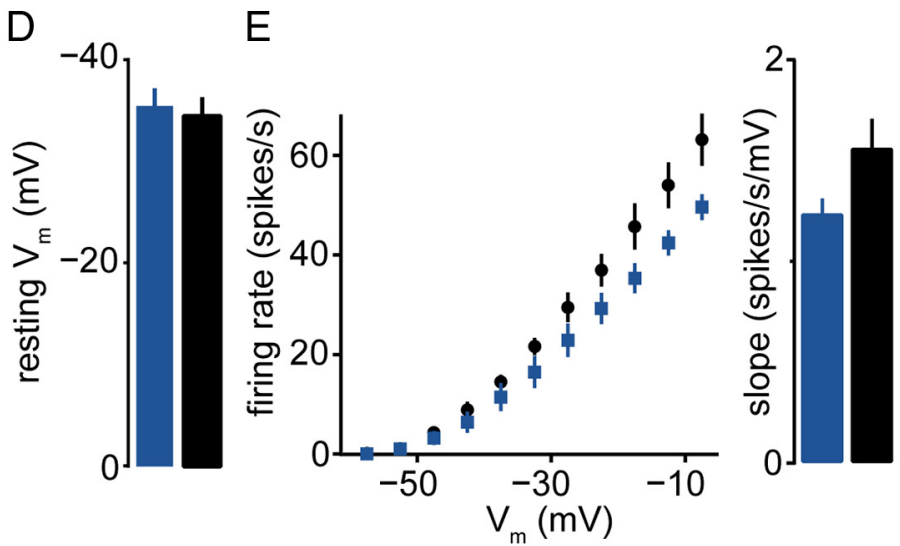

Figure 3. Odor responses of excitatory local neurons increase after chronic removal of some olfactory receptor neurons. $\boldsymbol{A}$, We recorded responses from eLNs while stimulating the palps with odors. Antennae were removed either acutely or chronically. $\boldsymbol{B}$, Responses of two typical eLNs to the same odor. One was recorded after acute antennal removal, the other after chronic removal. Note large spontaneous IPSPs (arrowhead), which are typical of eLNs. Rasters (below) show spiking activity in the same cells in five consecutive trials. Odor is ethyl acetate, $500 \mathrm{~ms}$ pulse. C, Average odor-evoked firing rates in eLNs in response to four odors (described in Fig. 1). Firing rate was averaged over a $500 \mathrm{~ms}$ window starting $100 \mathrm{~ms}$ after nominal odor onset. Firing rates are significantly higher after chronic versus acute antennal removal ( $p<0.05$, two-way ANOVA, $n=7$ acute and 6 chronic). $\boldsymbol{D}$, There is no significant difference in the resting potential of eLNs $(p>0.05, t$ test, $n=7$ and 6 for acute and chronic, respectively). $E$, There is no significant change in eLN excitability. Membrane potential changes were elicited by injecting current into the eLN soma, and firing rates were measured for each level of depolarization. The relationship between membrane potential and firing rate is not significantly different ( $p>0.05$ for all bins, $t$ test, $n=7$ acute and 6 chronic). Additionally, the bar graph (right) shows that the slope of a line fitted individually for each cell within the linear range $(-42.5$ to $-7.5 \mathrm{mV})$ is not significantly different between acute and chronic removal ( $p>0.05$, Mann-Whitney $U$ test).

propagation from the eLN soma to the site of electrical synapses, a mechanism that would not necessarily be bidirectional.

\section{Increased activity in local neurons}

Potentiated odor responses in PNs might also reflect increased odor-evoked activity in eLNs themselves, in addition to stronger eLN-to-PN coupling. We investigated this possibility by recording from eLNs and stimulating the maxillary palps with odors. Antennae were removed either acutely or chronically (Fig. 3A).

In experiments where the antennae were acutely removed, olfactory stimulation of the palps produced reliable depolarization and spiking in eLNs (Fig. $3 B$ ). This was expected because each eLN sends dendrites into all glomeruli and, thus, probably receives excitatory input from all glomeruli in the normal circuit. Chronically removing the antennae made odor responses in eLNs substantially larger, with each stimulus evoking more depolarization and more spiking (Fig. $3 B, C$ ). There was no significant change in the resting potential of eLNs (Fig. 3D). There was also no significant change in their intrinsic excitability (Fig. $3 E$ ). Together, these results imply that eLNs receive increased synaptic drive after chronic antennal removal. This may be due to potentiated electrical activity in deafferented PNs, which would be relayed onto eLNs via PN-to-eLN synapses.

In sum, our results imply that chronic loss of ORN input to some glomeruli alters the spread of excitation in several ways: (1) coupling from eLNs onto PNs is strengthened, (2) spontaneous activity in PNs is increased, and (3) odor-evoked eLN activity is increased.

\section{Specificity of plasticity}

These results raise the question of whether removing ORN input to a few glomeruli upregulates eLN input to PNs throughout the antennal lobe. Alternatively, eLN input might be upregulated specifically in deafferented glomeruli. We performed two experiments to investigate this possibility.

In the first experiment, we again took advantage of the fact that each glomerulus receives direct ORN input exclusively from either the antennae or the palps. In a previous set of experiments (Fig. 2), we had removed the antennae chronically and found that eLN-to-PN coupling was strengthened as a result. Most of the PNs we recorded from in that experiment were likely antennal PNs. We reasoned that if these changes are not specific to deafferented PNs, then removing the antennae should strengthen eLN-to-PN coupling onto palp PNs as well. To test this, we labeled palp PNs with GFP to record specifically from these cells. We made dual recordings from palp PNs and eLNs, and we compared the strength of coupling after acute versus chronic antennal removal (Fig. 4A). We found that eLN coupling onto palp PNs was significantly strengthened after chronic antennal removal, and this effect was comparable to the effect in antennal PNs (Fig. 
$4 B)$. This implies that eLN-to-PN coupling is strengthened globally, not just in deafferented glomeruli.

In the second experiment, we exploited the fact that most glomeruli (like glomerulus VM2) receive bilateral input from both antennae, but two olfactory glomeruli (including glomerulus V) receive input exclusively from the ipsilateral antenna (Stocker et al., 1990). Thus, by selectively removing the ipsilateral antenna, we can completely remove ORN input to glomerulus $\mathrm{V}$, while maintaining half the normal ORN input to glomerulus VM2. If chronically removing the ipsilateral antenna induces plasticity in $\mathrm{V}$ but not in VM2, then this would be evidence for specificity. To test this, we removed the ipsilateral antenna chronically in some flies and acutely in other flies. In all flies, the contralateral antenna was removed just before the experiment to remove all direct ORN input to VM2 PNs. Both palps were left intact so that we could drive input to eLNs with odors. First, we recorded from PNs in glomerulus VM2 (Fig. 4C). In these PNs, olfactory stimuli always produced a small depolarization, regardless of whether the ipsilateral antenna had been removed chronically or acutely (Fig. $4 D$ ). Spontaneous membrane potential fluctuations were also unaffected by chronic ipsilateral antennal removal (Fig. $4 E$ ). These results imply that chronically removing half of the normal ORN inputs to a PN is insufficient to trigger upregulation of eLN input to that PN. Next, we recorded from PNs in glomerulus $\mathrm{V}$ (Fig. $4 F)$. Overall, the odor responses of these PNs were not significantly potentiated after ipsilateral antennal removal (Fig. $4 G$ ). This implies that chronically removing all ORN input to just two glomeruli is insufficient to trigger full-blown plasticity in the eLN network, even in the deafferented glomeruli. This would also argue that this form of plasticity is a largely nonspecific process that affects either all glomeruli or no glomeruli.

Nevertheless, chronically removing the ipsilateral antenna did induce one significant change in glomerulus V PNs: spontaneous membrane fluctuations were significantly increased (Fig. 4H). This suggests that some expression mechanisms have a spatially specific component.

\section{Signals triggering plasticity}

We then asked what signals are responsible for triggering the functional changes that occur after ORNs are removed. Removing the antennae or maxillary palps completely removes the cell bodies of the associated ORNs, implying that spikes should be abolished. Indeed, we observed that spike-driven spontaneous EPSPs are absent in postsynaptic PNs after ORN somata are removed (Fig. 1B). Thus, the loss of electrical activity in ORNs might be the signal that induces these changes.
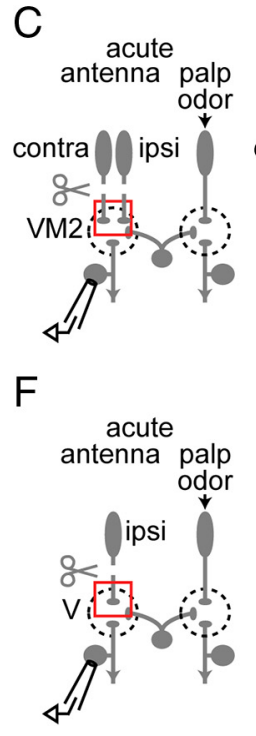
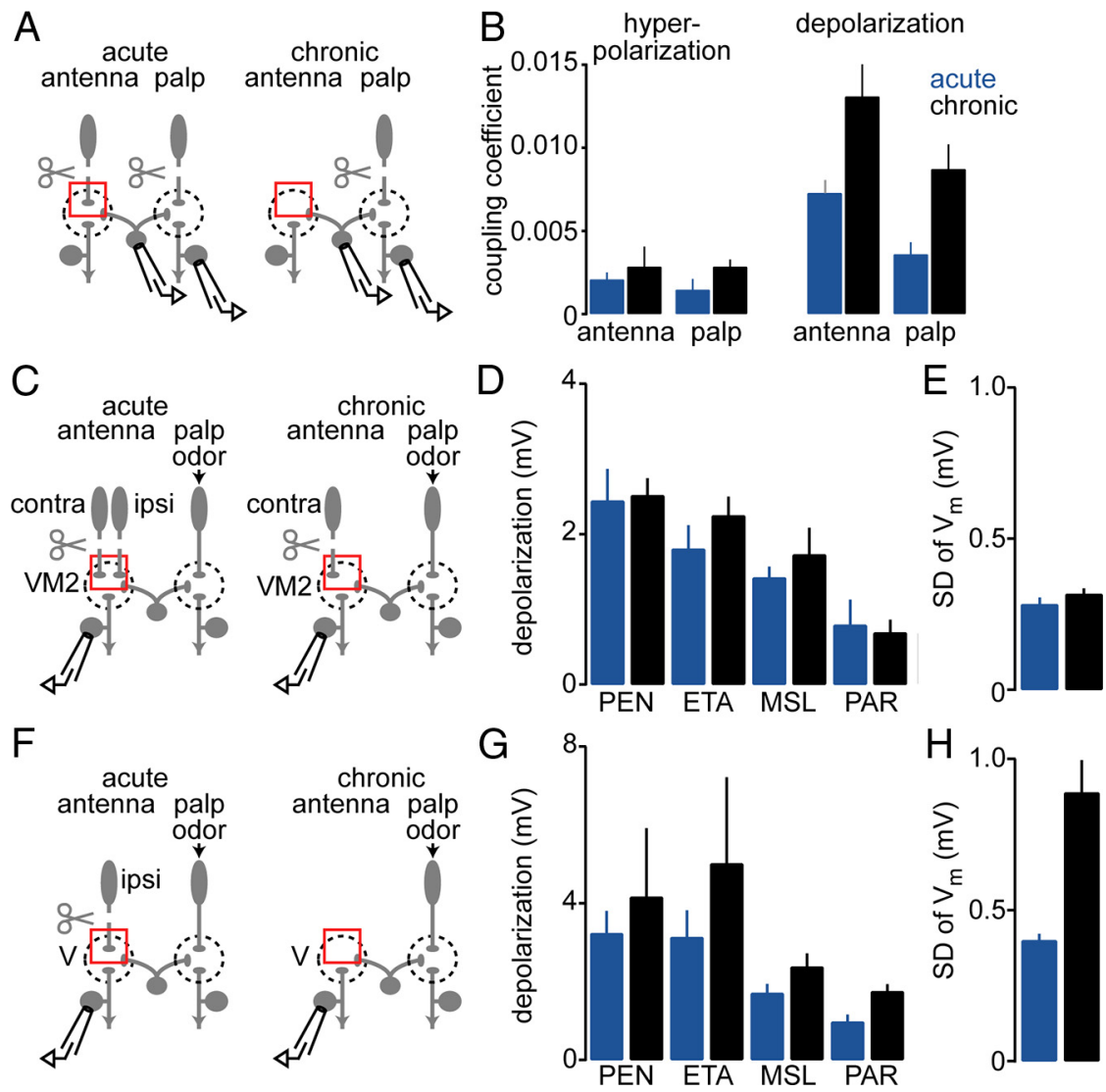

Figure 4. Plasticity is not specific to deafferented glomeruli. $\boldsymbol{A}$, We recorded simultaneously from an eLN and a palp PN (in chronically. Palps were removed acutely to minimize spontaneous activity. $\boldsymbol{B}$, The coupling coefficient of eLN-to-PN synapses is shown for four conditions: acute palp PN, chronic palp PN, acute antennal PN (reproduced from Fig. 20), and chronic antennal PN 0.006 , repeated-measures two-way ANOVA, $n=4$ acute and 5 chronic), just as for the antennal PNs. $C$, We recorded from PNs in the antennal glomerulus VM2. The ipsilateral antenna was removed either acutely or chronically. This glomerulus also receives ors (see Fig. 1) in VM2 PNs. There was no significant difference between acute and chronic conditions ( $p>0.05$, two-way acute and chronic ( $p>0.05$, two-way ANOVA, $n=6$ acute and 5 chronic). $\boldsymbol{H}$, Spontaneous membrane potential fluctuations were significantly increased after chronic ipsilateral antennal removal in V PNs ( $p<0.02, t$ test, $n=6$ acute and 5 chronic).

One way to investigate this idea is to silence ORNs using a mutation in an odorant receptor. Odorant receptor mutations abolish odor-evoked activity and decrease spontaneous firing in ORNs (Dobritsa et al., 2003; Olsen et al., 2007). Therefore, if plasticity is triggered by a decrease in electrical activity, an odorant receptor mutation should probably be sufficient to trigger it. To test this prediction, we used flies that harbor a mutation in the odorant receptor Or43b, which is normally expressed by ORNs presynaptic to the antennal glomerulus VM2. We labeled VM2 PNs with GFP so we could record specifically from these cells. The antennae were removed just before the experiment, and the palps were left intact (Fig. 5A). We found that odor-evoked depolarizations in Or43b mutant VM2 PNs were indistinguishable from depolarizations in wild-type VM2 PNs (Fig. $5 B, C$ ). Spontaneous activity in these PNs was also unaffected by the mutation (Fig. 5D). This result suggests that merely suppressing electrical activity in ORNs is not sufficient to trigger an upregulation of the eLN network. 


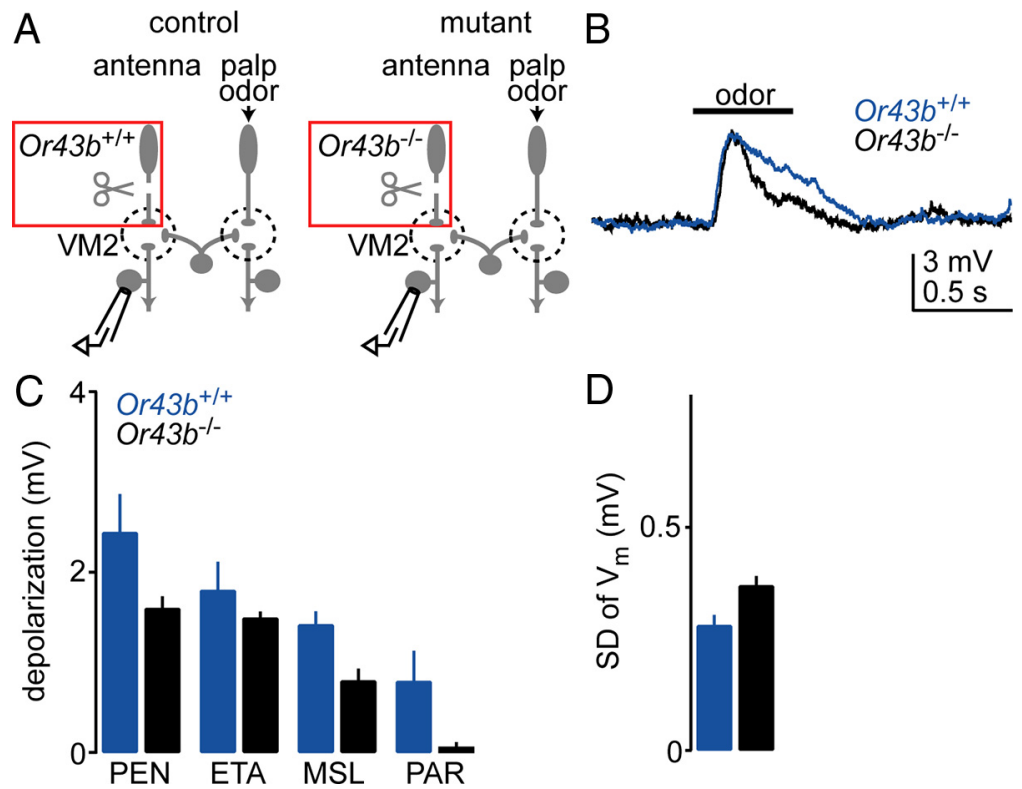

Figure 5. An odorant receptor mutation is insufficient to induce plasticity. $\boldsymbol{A}$, We recorded from PNs in glomerulus VM2 in control flies or flies that harbor a mutation in the odorant receptor $\mathrm{Or} 436$. This receptor is normally expressed in olfactory receptor neurons presynaptic to the antennal glomerulus VM2. Antennae were removed acutely and responses were recorded while applying odors to the palps. $\boldsymbol{B}, 0$ dor-evoked excitatory local neuron input to VM2 PNs was similar in Or $43 b$ mutants versus controls. C, Average membrane potential change in response to four odors (VM2 PNs; as in Fig. 1). There was no significant difference between responses in mutant and control flies ( $p>0.05$, two-way ANOVA, $n=5$ for mutant and control). $\boldsymbol{D}$, Spontaneous membrane potential fluctuations were also not significantly different ( $p>0.05, t$ test, $n=5$ for mutant and control).
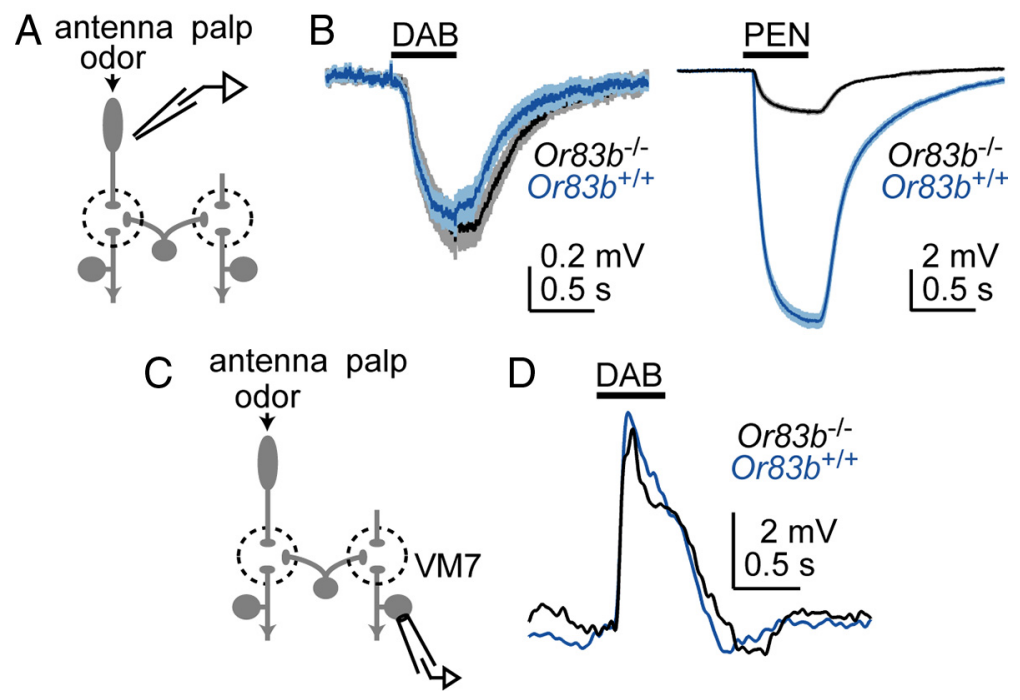

Figure 6. Abolishing olfactory receptor neuron spikes is insufficient to induce plasticity. $A$, To find an odor stimulus that activates solely Or83b-independent ORNs, we recorded field potentials from the antenna in both control flies and Or83b mutants. $B$, Average antennal field potential responses to the odor 1,4-diaminobutane (DAB) (at $10^{-5}$ dilution). These responses are not different in controls versus Or83b mutants. Because the antennal field potential is a good proxy for total ORN activity (0lsen et al., 2010), this result indicates that ORN responses to this stimulus are largely independent of Or83b. As a control, we verified that the response to a second odor, pentyl acetate (PEN), is substantially diminished in Or83b mutants, as expected from the fact that this stimulus drives activity in many Or83b-dependent ORNs (Hallem and Carlson, 2006). C, We recorded from PNs in the palp glomerulus VM7 while stimulating the antenna with DAB $\left(10^{-5}\right.$ dilution). Because spikes in VM7 ORNs are completely abolished by the Or83b mutation (Olsen et al., 2007), this experiment tests whether excitatory local neuron input to PNs is affected when spikes to that PN are eliminated. Palps were removed acutely to minimize spontaneous activity in the PN. $\boldsymbol{D}$, Representative recordings show that the response to $\mathrm{DAB}\left(10^{-5}\right.$ dilution) is similar in control and mutant VM7 PNs. Similar results were observed in multiple recordings ( $n=4$ control and 2 mutant).

Nevertheless, spontaneous activity is not completely abolished in Or43b mutant ORNs (Olsen et al., 2007). For this reason, we tried a more severe manipulation. We took advantage of the fact that a mutation in the Or83b gene completely abolishes spon- taneous as well as odor-evoked activity in the ORNs that normally express this gene (Larsson et al., 2004; Olsen et al., 2007). VM7 ORNs are among the ORNs that are silenced by this mutation (Olsen et al., 2007), and so we asked whether the mutation alters eLN input to VM7 PNs.

This experiment required that we activate eLNs via Or83b-independent ORNs. The odor 1,4-diaminobutane is likely to activate mainly Or83b-independent ORNs, based on published reports (Yao et al., 2005; Benton et al., 2009), and we confirmed that a low concentration of this odor ( $10^{-5}$ dilution) elicits a field potential response in the antenna that is unaffected by the Or83b mutation (Fig. 6A, B). Thus, ORN responses to this stimulus are similar in control and mutant flies. The key experiment was then to measure eLN input to VM7 PNs in response to this stimulus. We found that the responses of these PNs were very similar in controls and mutants (Fig. 6C,D). This result is striking because the mutant PNs had seen essentially zero ORN input during the life of the fly, and yet eLN input to these PNs was normal. Therefore, merely suppressing electrical activity in ORNs is not sufficient to induce functional changes in the antennal lobe.

\section{Blocking signaling from severed axons}

Because suppressing electrical activity was not sufficient, we wondered whether the trigger might be ORN death itself. Specifically, we considered the possibility that severed axons might produce a "death signal" that induces these changes. For example, there is evidence that severed ORN axons produce a death signal that recruits glial membranes into deafferented glomeruli. These glial membranes engulf severed ORN axons and clear them from the neuropil (Hoopfer et al., 2006; MacDonald et al., 2006; Logan and Freeman, 2007). By contrast, the axons of ORNs that are silenced by an odorant receptor mutation are not cleared from the antennal lobe (Olsen et al., 2007). This implies that severed axons send a specific signal that is not simply a consequence of reduced electrical activity in these axons.

Interestingly, when ORNs mis-express the neuroprotective protein $\mathrm{Wld}^{\mathrm{s}}$, glia do not extend membranes into the affected glomeruli, and ORN axons remain intact for weeks (Hoopfer et al., 2006; MacDonald et al., 2006). This suggests that $\mathrm{Wld}^{\mathrm{s}}$ can act in ORNs to block at least some of the signals sent by severed ORN axons.

We therefore asked whether expressing $\mathrm{Wld}^{\mathrm{s}}$ in ORNs also interferes with the induction of plasticity. We mis-expressed 
Wld $^{\text {s }}$ specifically in ORNs under Gal4/ UAS control, and as a negative control, we used flies lacking the Gal4 transgene. Antennae were removed either chronically or acutely. In control flies, as expected, severed ORN axons were cleared, whereas axons expressing Wld still remained intact after several days (Fig. 7A). In these two genotypes, we recorded from antennal $\mathrm{PNs}$ and compared the magnitude of depolarizations evoked by odor stimulation of the palps, with antennae removed either acutely or chronically (Fig. 7B). In control flies, olfactory stimulation of palp ORNs elicited the typical weak depolarization in antennal PNs after acute antennal removal but robust depolarization after chronic antennal removal (Fig. $7 C, D)$. By contrast, no plasticity was induced in the Wld ${ }^{\text {s }}$ flies: input from palp glomeruli onto antennal PNs was indistinguishable after acute versus chronic antennal removal (Fig. 7C,D).

Because severed axons are disconnected from the cell body, spikes should be absent from these axons. Consistent with this, we did not observe unitary spontaneous EPSPs in flies with severed axons, and this was true in both control and $\mathrm{Wld}^{\mathrm{s}}$-expressing flies (Fig. 7C). Thus, complete blockade of spiking is not sufficient to induce functional changes in the antennal lobe. Rather, these results suggest that functional changes are triggered by a signal which is produced by severed axons, and which is blocked by Wld ${ }^{\mathrm{S}}$.

\section{Blocking glial signaling}

Our findings show that expressing Wld $\mathrm{Wl}^{\mathrm{s}}$ in ORNs blocks the ability of severed axons to trigger plasticity. Expressing $\mathrm{Wld}^{\mathrm{s}}$ in ORNs also blocks glial recruitment in response to injury (Hoopfer et al., 2006; MacDonald et al., 2006). Therefore, we hypothesized that glia play a role in inducing plasticity in antennal lobe neurons.

Two types of glia are found in the antennal lobe neuropil: ensheathing glia and astrocytes (Doherty et al., 2009; Edwards and Meinertzhagen, 2010). Ensheathing glia wrap the glomerulus, whereas astrocytes invade the interior of the glomerulus. When ORN axons are severed, it is the ensheathing glia that extend membranes into deafferented glomeruli and engulf the severed axons. Endocytosis can be blocked in ensheathing glia by expressing a dominant temperature-sensitive mutant dynamin $\left(\right.$ shibire $\left.{ }^{\text {ts }}\right)$ in these cells and raising flies at a restrictive temperature that inhibits the function of the mutant dynamin. Similar to expressing Wld $\mathrm{W}^{\mathrm{s}}$ in ORNs, blocking endocytosis in ensheathing glia arrests the clearance of severed ORN axons (Doherty et al., 2009). We therefore asked whether blocking endocytosis in ensheathing glia also affects the induction of plasticity. We expressed shibire $^{\text {ts }}$ specifically in ensheathing glia and recorded from antennal PNs in these flies after antennae were removed
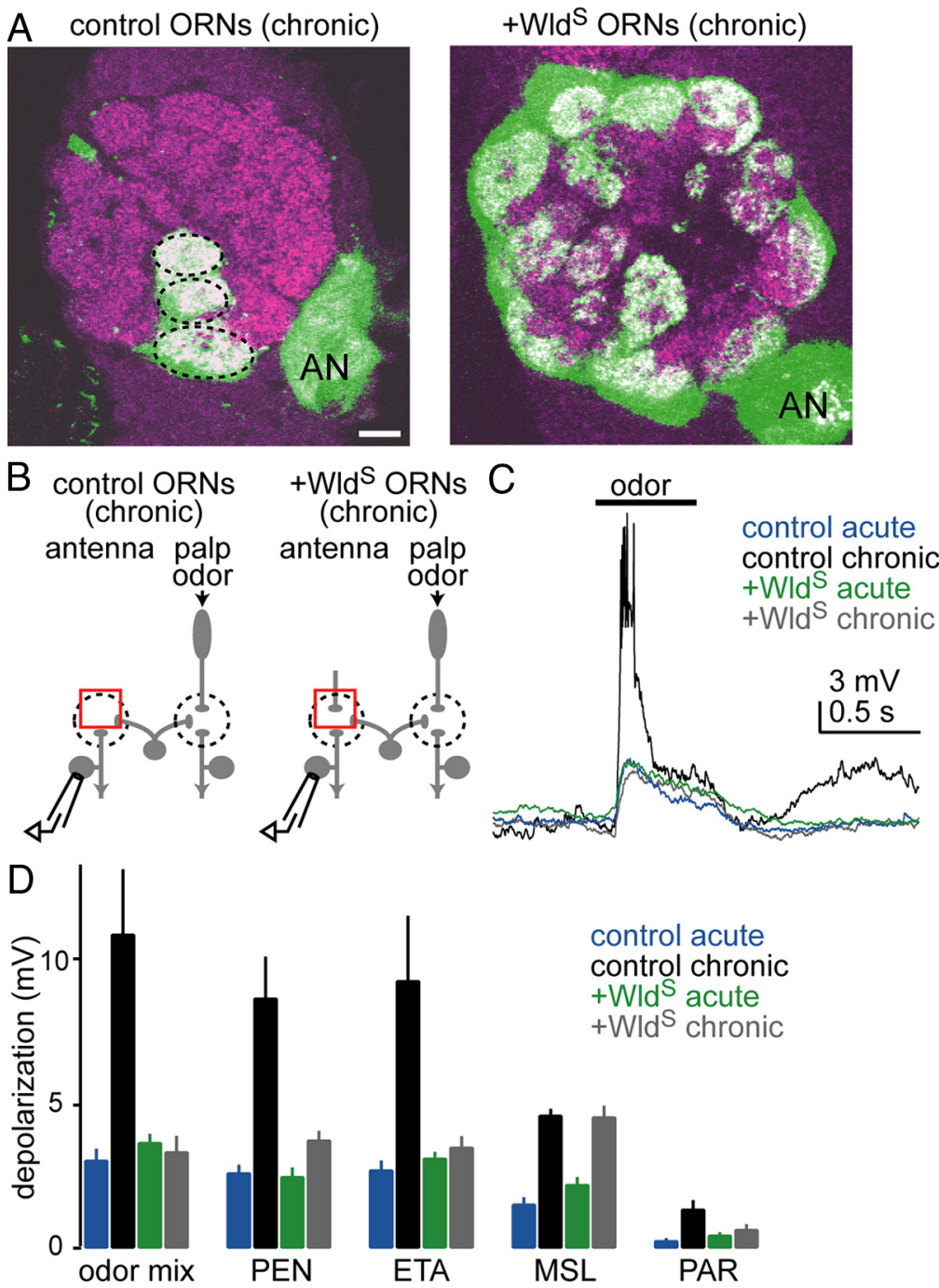

Figure 7. Plasticity is not induced if severed axons are prevented from recruiting glia. $\boldsymbol{A}$, Each image is a single confocal coronal ressed $\left(+\right.$ Wld $\left.^{5}\right)$ or not expressed (control) in all olfactory receptor neurons. Note that GFP signal is present only in palp (dashed lines) in the control fly, whereas it is present in all glomeruli in the fly expressing WId ${ }^{5}$. Scale bar, $10 \mu \mathrm{m} . \boldsymbol{B}, \mathrm{We}$ lps were stimulated with odors. C, Chronic antennal removal potentiates odor responses in deafferented projection neurons conditions. The difference between acute and chronic is significant in control flies but not in + Wld ${ }^{S}$ flies $\left(p<10^{-4}\right.$, two-way ANOVA, $p<0.05$, post hoc Tukey HSD, $n=11,8,10$, and 9 for control acute, control chronic, + Wld ${ }^{S}$ acute, and + Wld ${ }^{5}$ chronic, respectively). "Odor mix" is a blend designed to drive palp olfactory receptor neurons strongly (benzaldehyde, fenchone, ethyl butyrate, and pentyl acetate) (other odor abbreviations defined in Fig. 1).

(Fig. 8A). We divided flies into four experimental groups: flies were raised at either the restrictive temperature or the permissive temperature, and antennae were removed either acutely or chronically. The palps were left intact. As expected, flies raised at the permissive temperature resembled wild-type flies. In these control flies, olfactory stimulation of palp ORNs elicited weak depolarization in antennal PNs after acute antennal removal but robust depolarization after chronic antennal removal (Fig. 8B,C). By contrast, plasticity was blocked in flies raised at the restrictive temperature: here, stimulation of palp ORNs elicited only weak depolarization in antennal PNs, regardless of whether the antennae were removed acutely or chronically (Fig. $8 B, C$ ). These results demonstrate that the induction of plasticity requires endocytosis in ensheathing glia. 

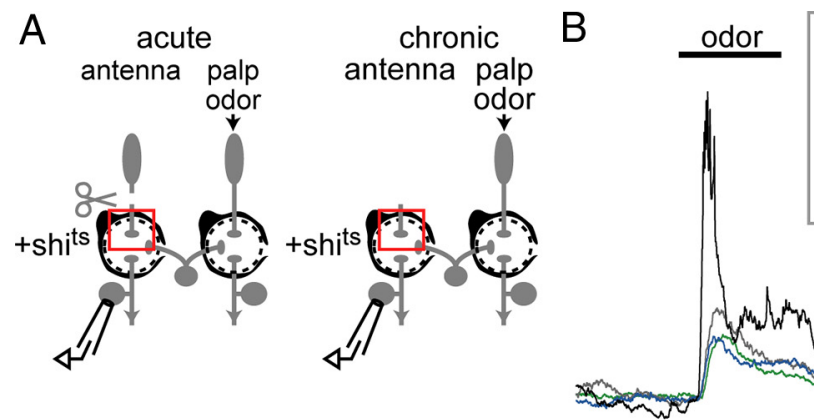

C
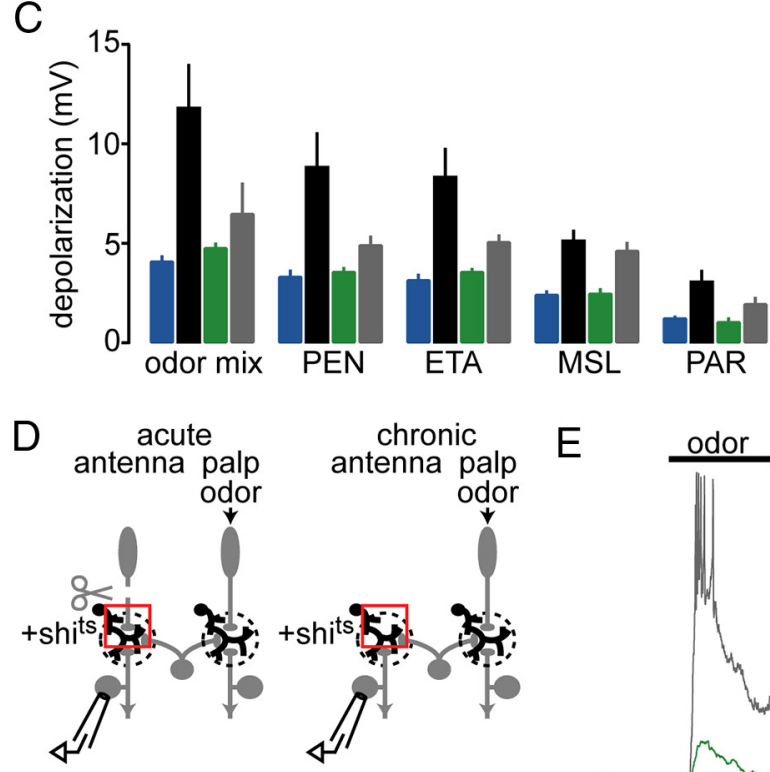

$\mathrm{F}$

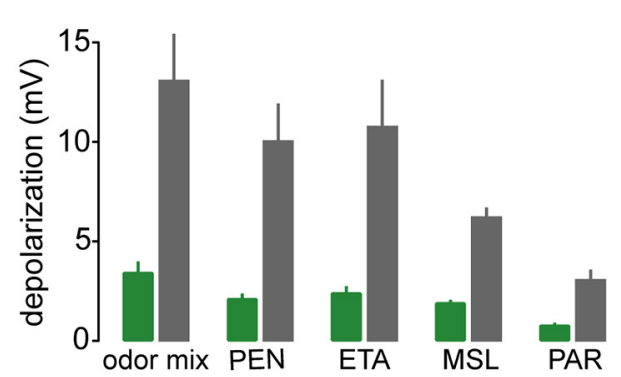

Figure 8. Plasticity requires endocytosis in ensheathing glia but not astrocytes. $\boldsymbol{A}$, We expressed temperature-sensitive dynamin (shibire ${ }^{\text {ts }}$ ) in ensheathing glia (depicted as cells surrounding each glomerulus). Antennae were removed and responses were recorded from antennal projection neurons while applying odors to the palps. Experiments were performed under four conditions: adult flies were cultured at either the permissive $\left(25^{\circ} \mathrm{C}\right)$ or the restrictive $\left(30^{\circ} \mathrm{C}\right)$ temperature, and antennae were removed either acutely or chronically. $\boldsymbol{B}$, Chronic antennal removal potentiates odor responses in deafferented projection neurons at permissive temperature but not at restrictive temperature. Inset shows spontaneous activity on a compressed time scale. $C$, Average membrane potential change in response to five odors under four experimental conditions. The difference between acute and chronic is significant at permissive but not at restrictive temperature ( $p<$ 0.05 , two-way ANOVA, $p<0.05$, post hoc Tukey HSD, $n=10,11,10$, and 15 for $25^{\circ} \mathrm{C}$ acute, $25^{\circ} \mathrm{C}$ chronic, $30^{\circ} \mathrm{C}$ acute, and $30^{\circ} \mathrm{C}$ chronic). $\boldsymbol{D}$, We now expressed shibire ${ }^{\text {ts }}$ in astrocytic glia (depicted as branching within the glomerulus). Antennae were removed and responses were recorded from antennal projection neurons while applying odors to the palps. Adult flies were cultured at the restrictive temperature $\left(30^{\circ} \mathrm{C}\right)$ and antennae were removed either acutely or chronically. $\boldsymbol{E}, 0$ dor responses are potentiated after chronic removal of antennae even at the restrictive temperature. $\boldsymbol{F}$, Average membrane potential change in response to five odors. Odor-evoked depolarization is significantly larger after chronic removal of antennae ( $p<0.05$, two-way ANOVA, $n=10$ and 9 for acute and chronic).
Unlike ensheathing glia, astrocytes do not show observable morphological responses to ORN death, and blocking endocytosis in astrocytes does not block clearance of severed axons (Doherty et al., 2009). We therefore asked whether blocking endocytosis in astrocytes affects the induction of plasticity. We expressed shibire ${ }^{\text {ts }}$ specifically in astrocytes and reared flies at the restrictive temperature to block endocytosis (Fig. 8D). We found that these flies resembled wild-type flies: stimulation of palp ORNs elicited weak depolarization in antennal PNs after acute antennal removal but robust depolarization after chronic antennal removal (Fig. $8 E, F)$. Thus, blocking endocytosis in astrocytes does not block the induction of plasticity. This result also shows that simply rearing flies at the restrictive temperature does not interfere with plasticity.

Together, these results show that ensheathing glia are specifically required for the functional changes in the antennal lobe circuit that follow removal of ORNs. These events require glial endocytosis, suggesting a role for an ORN-to-glial signaling pathway that requires endocytosis of a receptor on glial membranes.

\section{Discussion}

Our results demonstrate that when all the ORN afferents to a subset of glomeruli are removed, excitatory interactions between glomeruli become stronger. As a result, deafferented PNs acquire robust responses to odors. Whereas normal PNs respond selectively to different odor stimuli, deafferented PNs respond nonselectively. This presumably reflects the fact that each eLN arborizes in most or all glomeruli (Huang et al., 2010; Yaksi and Wilson, 2010). Thus, these PNs likely pool indirect excitatory input from all surviving ORNs.

The key finding of this study is that that removing ORN input causes an upregulation of excitatory connections between glomeruli. Previously, it was shown that overstimulating one ORN type causes an upregulation of inhibitory input to a glomerulus (Sachse et al., 2007). Both of these phenomena may be seen as forms of compensatory plasticity. Compensatory plasticity also occurs in the mammalian olfactory bulb at several synaptic sites (Guthrie et al., 1990; Wilson and Sullivan, 1995; Tyler et al., 2007).

\section{Induction of plasticity}

We found that silencing electrical activity in ORNs was not sufficient to induce the same functional changes produced by sev- 
ering ORN axons. This implies that the trigger is not the loss of electrical activity, but rather a molecular signal that is produced by severed axons. Mis-expressing Wld $^{S}$ in ORNs blocks induction, and this implies that Wld ${ }^{S}$ suppresses the signal that severed axons produce. Suppressing endocytosis in ensheathing glia also blocks induction. This suggests that the signal produced by severed axons acts on glial receptors that require endocytosis for signal transduction. It is interesting that blocking endocytosis in astrocytes had no effect, because astrocytes interact with neurons in other systems (Stevens, 2008). It is possible that astrocytes are involved in this process, but astrocytic endocytosis is not required.

It is notable that both the manipulations that blocked the induction of plasticity (mis-expressing Wld ${ }^{\mathrm{S}}$ in ORNs, or blocking endocytosis in ensheathing glia) also block the recruitment of ensheathing glia into deafferented glomeruli after ORNs are removed (Hoopfer et al., 2006; MacDonald et al., 2006; Doherty et al., 2009). This would appear to suggest that the same signal triggers both neural plasticity and morphological changes in glia. However, these signaling cascades clearly diverge: the recruitment of glial membranes to degenerating neurons is blocked by mutating the glial transmembrane receptor draper (Hoopfer et al., 2006; MacDonald et al., 2006), whereas draper is not required for the plasticity we describe here (data not shown). Interestingly, removing only one antenna was not sufficient to induce plasticity in glomerulus VM2 PNs. This manipulation kills half the ORNs that target these PNs. It should be noted that removing both palps kills fourfold fewer ORNs than removing one antenna, and this manipulation also affects fewer glomeruli, yet this was sufficient to induce plasticity in palp PNs. Removing both palps is also sufficient for glial mobilization and phagocytosis in the palp glomeruli (Doherty et al., 2009). Our results argue that the relevant factor is not the total number of afferents that are killed, but the proportion of live and dead axons in a given glomerulus. However, it also seems that killing all the ORNs that target a single glomerulus is not sufficient. This conclusion arises from our finding that removing the ipsilateral antenna did not produce potentiation in glomerulus $\mathrm{V}$ PNs, which receive strictly ipsilateral antennal input. This result implies that some minimum number of glomeruli must be completely deafferented to trigger the phenomenon we have described.

\section{Expression of plasticity}

Our results indicate that after some ORNs are chronically removed, several changes occur in the antennal lobe circuit over time. First, depolarization propagates more effectively from eLNs to PNs. This could reflect increased gap junctional conductance from eLNs onto PNs. However, we cannot exclude the possibility that it is the result of a change in the intrinsic properties of eLNs that produces better propagation of voltages from the eLN soma to the site of the eLN-PN gap junctions. In this latter scenario, there would not necessarily be a change in gap junction conductance. Because we cannot achieve good voltage clamp in eLNs, we could not evaluate these alternatives directly, but two pieces of evidence argue for a change in the gap junction itself. First, the gap junction subunit composition of these electrical connections is evidently changed, because we observed that electrical coupling from eLNs onto PNs is no longer completely dependent on the ShakB.neural subunit. Whereas in normal flies odor-evoked lateral excitation is abolished by the shakB ${ }^{2}$ mutation, which eliminates ShakB.neural (Yaksi and Wilson, 2010), odor-evoked lateral excitation is not abolished in mutant antennal PNs after chronic antennal removal (data not shown). Second, we found no significant change in any intrinsic properties of eLNs, including input resistance, resting potential, or excitability.

A second change that occurs in chronically deafferented PNs is that spontaneous membrane potential fluctuations are larger in these PNs compared with acutely deafferented PNs. This may result from the increased input from eLNs onto PNs.

A third change is that odors elicit stronger depolarization in eLNs. The intrinsic excitability of eLNs does not significantly increase, and therefore this change is likely caused by increased synaptic drive to eLNs. This potentiated synaptic drive may originate from PNs: because odor responses in deafferented PNs become larger after the induction of plasticity, and because PNs make chemical as well as electrical synapses onto eLNs, we would expect a net increase in the synaptic drive that PNs provide onto eLNs. In addition, it is possible that ORN-to-eLN synapses are potentiated.

In sum, the net effect of these changes is to produce more robust activity in chronically deafferented PNs, compared with acutely deafferented PNs. These findings also help explain why plasticity is expressed globally rather than locally: if eLNs are responding more robustly to odors, and each eLN innervates all glomeruli, then this increased excitation should propagate across the antennal lobe.

\section{Functional consequences}

Whereas normal PNs are selective for odor stimuli, the potentiated odor responses of deafferented PNs are comparatively nonspecific. This presumably reflects the fact that each eLN arborizes in most or all glomeruli (Huang et al., 2010; Yaksi and Wilson, 2010) and so likely pools input from all surviving ORN types. Nevertheless, the odor responses of deafferented PNs may still be useful from the perspective of higher olfactory brain regions. Because acutely deafferented PNs regain normal levels of activity over time, this type of plasticity should tend to restore normal levels of activity in higher olfactory regions. This might help maintain the sensitivity of these regions to sensory signals, or maintain tropic support to these regions.

More broadly, we speculate that the phenomenon we describe here might reflect a general injury response in the Drosophila nervous system, and perhaps also a phenomenon that occurs during normal nervous system development. By triggering the upregulation of specific interactions between surviving neurons following the death of other neurons, this mechanism might help increase the number of neurons that are driven by active afferents. This could be a generally useful adaptation to neuronal death because it should tend to maintain total neural activity within a normal dynamic range.

\section{Significance for other systems}

The reorganization of central sensory representations following changes in sensory input is generally thought to reflect changes in the strength of chemical synapses. Our results suggest that central electrical synapses can also be persistently altered following sensory deafferentation. It is well known that neuromodulators can produce short-term changes in the strength of electrical synapses, as illustrated by studies in the vertebrate retina and crustacean stomatogastric ganglion (Harris-Warrick et al., 1998; Bloomfield and Völgyi, 2009). There are fewer examples of long-term changes in electrical synapse strength, but a growing literature suggests that this may be a fundamental mechanism of neural plasticity (Yang et al., 1990; Pereda et al., 1992, 1998; Landisman and Connors, 2005). 
The reorganization of central sensory representations following sensory deafferentation is sometimes assumed to be triggered by reduced electrical activity, not cell death. However, there is growing evidence that changes in electrical activity may produce synaptic plasticity via signaling pathways that are also linked to injury and inflammation (Corriveau et al., 1998; Huh et al., 2000; Stellwagen and Malenka, 2006; Kaneko et al., 2008). Thus, changes in electrical activity can produce synaptic plasticity by "co-opting" signaling systems that are involved in injury responses. Our results show that, in the Drosophila antennal lobe, some functional rearrangements following deafferentation can be specific responses to cell death signals, and are not necessarily induced by electrical silencing. In this study, we were able to disambiguate reduced electrical activity from cell death because we used genetic tools to create "undead" severed axons. Our results are reminiscent of studies in vertebrates showing that sensory afferent death can produce changes in target brain regions that are not mimicked by electrical silencing using pharmacological manipulations (Campos-Torres et al., 2005; Harris et al., 2008).

Finally, our findings provide a new window on neural-glial interactions. In mammals, there is good evidence that glia can modulate synaptic transmission and neural excitability (Halassa and Haydon, 2010). In both mammals and in Drosophila, glia also play important roles following injury (Logan and Freeman, 2007; Barres, 2008). In particular, there are many instances of sensory afferent injury causing morphological changes in glia and glial proliferation in target brain regions (Pinching and Powell, 1972; Anders and Johnson, 1990; Rubel and MacDonald, 1992; Canady et al., 1994). However, it is not entirely clear how such glial responses might affect neuronal physiology and sensory codes in these brain regions. Our results illustrate specific cellular and synaptic changes in a sensory circuit that result from glial responses to sensory afferent injury. More broadly, our results illustrate the power of Drosophila as a genetically tractable model for studying neural-glial interactions in vivo.

\section{References}

Anders JJ, Johnson JA (1990) Transection of the rat olfactory nerve increases glial fibrillary acidic protein immunoreactivity from the olfactory bulb to the piriform cortex. Glia 3:17-25.

Barres BA (2008) The mystery and magic of glia: a perspective on their roles in health and disease. Neuron 60:430-440.

Benton R, Vannice KS, Gomez-Diaz C, Vosshall LB (2009) Variant ionotropic glutamate receptors as chemosensory receptors in Drosophila. Cell 136:149-162.

Berdnik D, Chihara T, Couto A, Luo L (2006) Wiring stability of the adult Drosophila olfactory circuit after lesion. J Neurosci 26:3367-3376.

Bloomfield SA, Völgyi B (2009) The diverse functional roles and regulation of neuronal gap junctions in the retina. Nat Rev Neurosci 10:495-506.

Campos-Torres A, Touret M, Vidal PP, Barnum S, de Waele C (2005) The differential response of astrocytes within the vestibular and cochlear nuclei following unilateral labyrinthectomy or vestibular afferent activity blockade by transtympanic tetrodotoxin injection in the rat. Neuroscience 130:853-865.

Canady KS, Olavarria JF, Rubel EW (1994) Reduced retinal activity increases GFAP immunoreactivity in rat lateral geniculate nucleus. Brain Res 663:206-214.

Chou YH, Spletter ML, Yaksi E, Leong JC, Wilson RI, Luo L (2010) Diversity and wiring variability of olfactory local interneurons in the Drosophila antennal lobe. Nat Neurosci 13:439-449.

Corriveau RA, Huh GS, Shatz CJ (1998) Regulation of class I MHC gene expression in the developing and mature CNS by neural activity. Neuron 21:505-520.

Couto A, Alenius M, Dickson BJ (2005) Molecular, anatomical, and functional organization of the Drosophila olfactory system. Curr Biol 15:1535-1547.
Dobritsa AA, van der Goes van Naters W, Warr CG, Steinbrecht RA, Carlson JR (2003) Integrating the molecular and cellular basis of odor coding in the Drosophila antenna. Neuron 37:827-841.

Doherty J, Logan MA, Taşdemir OE, Freeman MR (2009) Ensheathing glia function as phagocytes in the adult Drosophila brain. J Neurosci 29:4768-4781.

Dubnau J, Chiang AS, Grady L, Barditch J, Gossweiler S, McNeil J, Smith P, Buldoc F, Scott R, Certa U, Broger C, Tully T (2003) The staufen/ pumilio pathway is involved in Drosophila long-term memory. Curr Biol 13:286-296.

Edwards TN, Meinertzhagen IA (2010) The functional organisation of glia in the adult brain of Drosophila and other insects. Prog Neurobiol 90:471-497.

Elmore T, Ignell R, Carlson JR, Smith DP (2003) Targeted mutation of a Drosophila odor receptor defines receptor requirement in a novel class of sensillum. J Neurosci 23:9906-9912.

Feldman DE (2009) Synaptic mechanisms for plasticity in neocortex. Annu Rev Neurosci 32:33-55.

Feldman DE, Brecht M (2005) Map plasticity in somatosensory cortex. Science 310:810-815.

Fishilevich E, Domingos AI, Asahina K, Naef F, Vosshall LB, Louis M (2005) Chemotaxis behavior mediated by single larval olfactory neurons in Drosophila. Curr Biol 15:2086-2096.

Guthrie KM, Wilson DA, Leon M (1990) Early unilateral deprivation modifies olfactory bulb function. J Neurosci 10:3402-3412.

Halassa MM, Haydon PG (2010) Integrated brain circuits: astrocytic networks modulate neuronal activity and behavior. Annu Rev Physiol 72:335-355

Hallem EA, Carlson JR (2006) Coding of odors by a receptor repertoire. Cell 125:143-160.

Harris JA, Iguchi F, Seidl AH, Lurie DI, Rubel EW (2008) Afferent deprivation elicits a transcriptional response associated with neuronal survival after a critical period in the mouse cochlear nucleus. J Neurosci 28:10990-11002.

Harris-Warrick RM, Johnson BR, Peck JH, Kloppenburg P, Ayali A, Skarbinski J (1998) Distributed effects of dopamine modulation in the crustacean pyloric network. Ann N Y Acad Sci 860:155-167.

Hoopfer ED, McLaughlin T, Watts RJ, Schuldiner O, O'Leary DD, Luo L (2006) Wlds protection distinguishes axon degeneration following injury from naturally occurring developmental pruning. Neuron 50:883-895.

Huang J, Zhang W, Qiao W, Hu A, Wang Z (2010) Functional connectivity and selective odor responses of excitatory local interneurons in Drosophila antennal lobe. Neuron 67:1021-1033.

Huh GS, Boulanger LM, Du H, Riquelme PA, Brotz TM, Shatz CJ (2000) Functional requirement for class I MHC in CNS development and plasticity. Science 290:2155-2159.

Ito K, Urban J, Technau GM (1995) Distribution, classification and development of Drosophila glial cells in the late embryonic and early larval ventral nerve cord. Roux's Arch Dev Biol 204:284-307.

Kaneko M, Stellwagen D, Malenka RC, Stryker MP (2008) Tumor necrosis factor-alpha mediates one component of competitive, experiencedependent plasticity in developing visual cortex. Neuron 58:673-680.

Kazama H, Wilson RI (2008) Homeostatic matching and nonlinear amplification at identified central synapses. Neuron 58:401-413.

Kazama H, Wilson RI (2009) Origins of correlated activity in an olfactory circuit. Nat Neurosci 12:1136-1144.

Kitamoto T (2001) Conditional modification of behavior in Drosophila by targeted expression of a temperature-sensitive shibire allele in defined neurons. J Neurobiol 47:81-92.

Landisman CE, Connors BW (2005) Long-term modulation of electrical synapses in the mammalian thalamus. Science 310:1809-1813.

Larsson MC, Domingos AI, Jones WD, Chiappe ME, Amrein H, Vosshall LB (2004) Or83b encodes a broadly expressed odorant receptor essential for Drosophila olfaction. Neuron 43:703-714.

Lee T, Luo L (1999) Mosaic analysis with a repressible cell marker for studies of gene function in neuronal morphogenesis. Neuron 22:451-461.

Logan MA, Freeman MR (2007) The scoop on the fly brain: glial engulfment functions in Drosophila. Neuron Glia Biol 3:63-74.

MacDonald JM, Beach MG, Porpiglia E, Sheehan AE, Watts RJ, Freeman MR (2006) The Drosophila cell corpse engulfment receptor Draper mediates glial clearance of severed axons. Neuron 50:869-881. 
Olsen SR, Bhandawat V, Wilson RI (2007) Excitatory interactions between olfactory processing channels in the Drosophila antennal lobe. Neuron 54:89-103.

Olsen SR, Bhandawat V, Wilson RI (2010) Divisive normalization in olfactory population codes. Neuron 66:287-299.

Pereda A, Triller A, Korn H, Faber DS (1992) Dopamine enhances both electrotonic coupling and chemical excitatory postsynaptic potentials at mixed synapses. Proc Natl Acad Sci U S A 89:12088-12092.

Pereda AE, Bell TD, Chang BH, Czernik AJ, Nairn AC, Soderling TR, Faber DS (1998) $\mathrm{Ca}^{2+} /$ calmodulin-dependent kinase II mediates simultaneous enhancement of gap-junctional conductance and glutamatergic transmission. Proc Natl Acad Sci U S A 95:13272-13277.

Pinching AJ, Powell TP (1972) A study of terminal degeneration in the olfactory bulb of the rat. J Cell Sci 10:585-619.

Rubel EW, MacDonald GH (1992) Rapid growth of astrocytic processes in N. magnocellularis following cochlea removal. J Comp Neurol 318:415-425.

Sachse S, Rueckert E, Keller A, Okada R, Tanaka NK, Ito K, Vosshall LB (2007) Activity-dependent plasticity in an olfactory circuit. Neuron 56:838-850.

Shang Y, Claridge-Chang A, Sjulson L, Pypaert M, Miesenböck G (2007) Excitatory local circuits and their implications for olfactory processing in the fly antennal lobe. Cell 128:601-612.

Smith GB, Heynen AJ, Bear MF (2009) Bidirectional synaptic mechanisms of ocular dominance plasticity in visual cortex. Philos Trans R Soc Lond B Biol Sci 364:357-367.

Stellwagen D, Malenka RC (2006) Synaptic scaling mediated by glial TNFalpha. Nature 440:1054-1059.

Stevens B (2008) Neuron-astrocyte signaling in the development and plasticity of neural circuits. Neurosignals 16:278-288.

Stocker RF, Lienhard MC, Borst A, Fischbach KF (1990) Neuronal architecture of the antennal lobe in Drosophila melanogaster. Cell Tissue Res 262:9-34.
Stocker RF, Heimbeck G, Gendre N, de Belle JS (1997) Neuroblast ablation in Drosophila P[GAL4] lines reveals origins of olfactory interneurons. J Neurobiol 32:443-456.

Strausfeld NJ (1976) Atlas of an insect brain. Berlin: Springer.

Tanaka NK, Awasaki T, Shimada T, Ito K (2004) Integration of chemosensory pathways in the Drosophila second-order olfactory centers. Curr Biol 14:449-457.

Tropea D, Van Wart A, Sur M (2009) Molecular mechanisms of experiencedependent plasticity in visual cortex. Philos Trans R Soc Lond B Biol Sci 364:341-355

Tyler WJ, Petzold GC, Pal SK, Murthy VN (2007) Experience-dependent modification of primary sensory synapses in the mammalian olfactory bulb. J Neurosci 27:9427-9438.

Vosshall LB, Wong AM, Axel R (2000) An olfactory sensory map in the fly brain. Cell 102:147-159.

Wiesel TN (1982) Postnatal development of the visual cortex and the influence of environment. Nature 299:583-591.

Wilson DA, Sullivan RM (1995) The D2 antagonist spiperone mimics the effects of olfactory deprivation on mitral/tufted cell odor response patterns. J Neurosci 15:5574-5581.

Wilson RI, Laurent G (2005) Role of GABAergic inhibition in shaping odorevoked spatiotemporal patterns in the Drosophila antennal lobe. J Neurosci 25:9069-9079.

Yaksi E, Wilson RI (2010) Electrical coupling between olfactory glomeruli. Neuron 67:1034-1047.

Yang XD, Korn H, Faber DS (1990) Long-term potentiation of electrotonic coupling at mixed synapses. Nature 348:542-545.

Yao CA, Ignell R, Carlson JR (2005) Chemosensory coding by neurons in the coeloconic sensilla of the Drosophila antenna. J Neurosci 25:83598367.

Yu D, Ponomarev A, Davis RL (2004) Altered representation of the spatial code for odors after olfactory classical conditioning; memory trace formation by synaptic recruitment. Neuron 42:437-449. 